\title{
A critical threshold of exercise capacity in the ventilatory response to exercise in heart failure
}

\author{
Simon W Davies, T Malcolm Emery, Mark I L Watling, G Wannamethee, \\ David P Lipkin
}

\begin{abstract}
During exercise patients with chronic left heart failure ventilate more than normal individuals at the same workload; the ratio of minute ventilation to minute production of carbon dioxide $\left(\dot{\mathrm{V}} / \dot{V}_{\mathrm{CO}_{2}}\right)$ is increased. The relation between increased $\dot{\mathrm{V}} / \mathrm{V}_{\mathrm{CO}_{2}}$, severity of heart failure, and exercise capacity has not been defined. $\dot{V} \mathrm{E} / \dot{V}_{\mathrm{CO}_{2}}$ was measured in 47 patients with chronic left heart failure (New York Heart Association grades II and III) and in 1009 healthy controls. Exercise capacity was assessed by peak oxygen consumption ( $\dot{V}_{2} \max$ ) during progressive exercise. In the controls $\mathrm{Vo}_{2} \mathrm{max}$ ranged from 25 to $93 \mathrm{ml} / \mathrm{kg}$ / min; $\dot{V}_{E} / \dot{V}_{\mathrm{CO}_{2}}$ was $17-36$ and did not correlate with $\dot{V}_{2} \max$. In chronic left heart failure the $\mathrm{Vo}_{2} \max$ ranged from 9 to $29 \mathrm{ml} / \mathrm{kg} / \mathrm{min} ; \dot{V} / \dot{V}_{\mathrm{CO}_{2}}$ was $22-42$ and correlated strongly with $\dot{V}_{2}$ max. End tidal carbon dioxide and respiratory rate at peak exercise were similar in the controls and patients with chronic left heart failure. The increase in $\dot{\mathrm{V}} / \mathbf{V}_{\mathrm{CO}}$ on exercise in chronic left heart failure indicates increased physiological dead space, presumably caused by a ventilationperfusion mismatch. In the controls and patients with chronic left heart failure the relation of $\dot{V} / \dot{V}_{\mathrm{CO}_{2}}$ to $\dot{\mathrm{Vo}}_{2} \max$ was curvilinear with a threshold of $\mathrm{Vo}_{2} \mathrm{max}$ below which $\dot{V} / V \mathrm{CO}_{2}$ started to rise above the normal range. This point of inflection may be explained by the existence of a critical level of cardiac function necessary to perfuse adequately all lung zones on exercise.
\end{abstract}

Cardiac Department The Royal Free Hospital, London $S$ W Davies D P Lipkin

City Health Care, London

T M Emery

M I L Watling

Department of

Community Medicine

and Public Health,

The Royal Free

Hospital Medical

School, London

G Wannamethee

Correspondence to

Dr Simon W Davies,

Dr Simon W Davies,

The London Chest Hospital,

The London

Bonner Road,

Accepted for publication

20 November 1990

Dyspnoea is a major symptom of chronic left heart failure and may severely limit the exercise capacity of the patient. ${ }^{1}$ The pathophysiological basis of this symptom is not understood, though many explanations have been proposed. In patients with acute pulmonary oedema a rapid rise in pulmonary venous pressure leads to the accumulation of interstitial fluid, decreased lung compliance, and increased airway resistance. ${ }^{23}$ This simple explanation, however, does not apply to patients with chronic left heart failure, in whom there is no apparent relation between dyspnoea and pulmonary venous pressure. ${ }^{45}$

Numerous studies have reported an increased ventilatory response to exercise in heart failure: patients with chronic heart failure ventilate more than healthy controls at the same external workload. ${ }^{6-8}$ This increased ventilation may be expressed as the ratio of the minute ventilation to the minute production of carbon dioxide $\left(\dot{\mathrm{V}} / \dot{\mathrm{V}}_{\mathrm{CO}}\right)$, which standardises for any differences in metabolic rate. ${ }^{910}$ It has recently been suggested that the increased $\dot{\mathrm{VE}} / \mathrm{VCO}_{2}$ is associated with dyspnoea. ${ }^{11}$ The exact relation between the value of the $\dot{\mathrm{VE}} / \mathrm{V} \mathrm{CO}_{2}$ ratio, the functional state of the patient, and the level of dyspnoea is not known, however. We have therefore examined the relation between $\dot{\mathrm{V}}_{\mathrm{E}} / \dot{\mathrm{V}}_{\mathrm{CO}}$ and exercise capacity across a range of severity of chronic heart failure and in a large group of healthy controls of different levels of fitness to determine the relation between exercise capacity, exercise hyperpnoea, and the efficiency of gas exchange.

\section{Patients and methods}

PATIENTS

We recruited 47 patients with chronic left heart failure in New York Heart Association categories II or III from outpatient clinics. Impaired left ventricular function was assessed both by radionuclide gated blood pool scanning and by echocardiographic determination of ejection fraction; the left ventricular ejection fraction by both methods was $<50 \%$. Patients with valvar heart disease were excluded. There was no evidence of primary lung disease as judged by history, clinical examination, and chest $x$ ray, and each patient achieved at least $70 \%$ of the predicted normal values on lung function tests, static lung volumes, airways resistance, and carbon monoxide gas transfer. Patients with disturbance of balance or with musculo-skeletal problems that might limit exercise were excluded. The project was approved by the local ethics committee and all patients gave written consent.
Healthy individuals with no history of cardiopulmonary disease were recruited from a health screening service. Physical examination, resting and exercise electrocardiograms, chest $x$ ray, and lung function tests were all normal.

\section{EXERCISE TESTING}

All subjects performed progressive maximal symptom limited exertion. Pulse, respiratory rate, blood pressure, and the 12 lead electrocardiogram were recorded in each stage. Subjects performed a familiarisation maximal test with expired gas analysis 2-14 days before the study. Patients were given the usual cardiac medications that day. All subjects were tested at least two hours after eating. 
Table 1 Main characteristics (range (median)) of patients and healthy controls

\begin{tabular}{lll}
\hline & $\begin{array}{l}\text { Patients } \\
(n=47)\end{array}$ & $\begin{array}{l}\text { Controls } \\
(n=1009)\end{array}$ \\
\hline Age (yr) & $47-78(65)$ & $25-70(45)$ \\
Body mass index & $18 \cdot 2-29 \cdot 8(22 \cdot 7)$ & $13 \cdot 7-45 \cdot 6(24 \cdot 7)$ \\
LVEF (\%, by MUGA) & $5-48(24)$ & $-1 \cdot 5-6 \cdot 4(3 \cdot 8)$ \\
FEV $(1)$ & $1 \cdot 2-3 \cdot 7(2 \cdot 3)$ & $75-129(98)$ \\
FEV $(\%$ predicted) & $76-124(92)$ & $2 \cdot 3-7 \cdot 6(4 \cdot 7)$ \\
FVC (1) & $1 \cdot 5-5 \cdot 6(3 \cdot 1)$ & $77-128(99)$ \\
FVC (\% predicted) & $71-117(83)$ & $4 \cdot 7-11 \cdot 9(7 \cdot 4)$ \\
VA (1) & $3 \cdot 2-7 \cdot 9(5 \cdot 4)$ & $74-132(102)$ \\
VA (\% predicted) & $71-125(94)$ & \\
\hline
\end{tabular}

$\mathrm{FEV}_{1}$, forced expiratory volume in one second; FVC, forced vital capacity; LVEF, left ventricular ejection fraction determined by radionuclide gated blood pool scanning MUGA, multigated acquisition; VA, alveolar volume determined as lung volume accessible to helium gas.

Expired gases were analysed at rest until a steady state was achieved, and then continuously during exercise and the recovery phase. Subjects wore a mouthpiece with low resistance Hans Rudolf spiral non-return valve and there was a low volume of dead space in the circuit. Expired gas passed through a mixing box and was sampled by four channel mass spectrometer (AirSpec MGA200), with the output passing to analogue-to-digital converter and on line computer. Ventilation was measured by argon dilution. ${ }^{12}$ Oxygen production $(\mathrm{ml} / \mathrm{kg} / \mathrm{min})$, carbon dioxide production $(\mathrm{ml} /$ $\mathrm{kg} / \mathrm{min}$ ), and minute ventilation $(1 / \mathrm{min})$ were averaged and calculated every 10 seconds by the on line computer during the test. We analysed the results by taking mean values over the last minute of exercise. Respiratory rate and end tidal carbon dioxide were recorded over the last 30 seconds of each stage and over the last minute of exercise.

End tidal carbon dioxide was measured at the mouthpiece by an infrared capnograph (Godart) and a corrected estimate of mean arterial $\mathrm{PCO}_{2}$ was obtained by the Jones formula. ${ }^{13}$ Arterial oxygen saturation was monitored by pulse oximetry at the ear lobe (Radiometer). In a subgroup of 10 patients the oxygen saturation and end tidal carbon dioxide were validated against arterialised ear lobe blood samples analysed in a Radiometer ABL3 machine.

Measurements of $\dot{\mathrm{V}} / \mathrm{V}_{\mathrm{CO}}$ and of end tidal carbon dioxide were used to calculate the ratio of dead space ventilation to total minute ventilation $\left(\dot{V} D / \dot{V}_{E}\right)$ according to the Bohr equation. ${ }^{14} 15$ We calculated tidal volume and thus the mean dead space per breath $(\mathrm{VD} /$ breath) from the measured respiratory rate and minute ventilation:

$$
\begin{aligned}
& \mathbf{V T}=\dot{\mathrm{V}} \mathbf{E} / \mathbf{R R} \\
& \mathbf{V D} / \text { breath }=\mathrm{VT} \times\left(\dot{V}_{\mathbf{D}} / \dot{V}_{\mathbf{E}}\right) .
\end{aligned}
$$

Table 2 Reproducibility of respiratory measurements on repeat testing in patients

\begin{tabular}{lll}
\hline Measurement & $\begin{array}{c}\text { Mean difference } \\
\text { (test 3-test 2) }\end{array}$ & $\begin{array}{c}\text { SD of } \\
\text { differences }\end{array}$ \\
\hline Exercise duration $(\mathrm{min})$ & +0.26 & \pm 1.62 \\
Peak oxygen consumption $\left(\mathrm{VO}_{2} \mathrm{max}\right)(\mathrm{ml} / \mathrm{kg} / \mathrm{min})$ & -0.19 & \pm 1.53 \\
Peak ventilation $(1 / \mathrm{min})$ & -0.23 & \pm 6.7 \\
\hline
\end{tabular}

\section{REPRODUCIBILITY}

We determined the reproducibility of ventilatory measurements on repeated testing by performing a third non-invasive maximal exercise study $1-5$ weeks after the second study in all 47 patients with heart failure. Reproducibility data are presented as the mean difference (test 3 - test 2) \pm the SD of the differences.

\section{ANALYSIS}

In the 1009 controls univariate relations between the variables were assessed by Pearson's product-moment correlation coefficient. Adjustment for the possible confounding effects of age and weight (body mass index) was made by multiple linear regression analysis. We examined the magnitudes of weak but statistically significant correlations with $\dot{\mathrm{Vo}}_{2} \max$ within the large group of controls by dividing the group into deciles of $\mathrm{VO}_{2} \max$ and calculating the mean value of the given variable for each decile.

We used non-parametric statistical analysis for the small group of patients with chronic left heart failure. Values of variables are given as median and range. Correlations were examined by the Spearman rank correlation coefficient $R$.

\section{Results}

\section{GROUP CHARACTERISTICS}

The patients were aged 47-78 (median 65 ) and the normal healthy subjects were aged 25-70 (median 45). Though the patients with chronic left heart failure tended to be older this difference was not statistically significant. Static lung volumes were all approximately $80-85 \%$ of the predicted normal value in the patient group (table 1).

\section{REPRODUCIBILITY STUDIES}

There were no significant differences between resting or exercise values for any of the ventilatory variables between the two studies in the 47 patients with chronic left heart failure. Table 2 gives the mean differences and the standard deviation of the differences.

\section{PATIENTS WITH CHRONIC HEART FAILURE}

Peak oxygen consumption ( $\mathrm{V}_{2}$ max) ranged from 9 to 29 (median 14) $\mathrm{ml} / \mathrm{kg} / \mathrm{min}$. Table 3 gives the results of exercise testing and the respiratory variables calculated from the exercise data. The ratio $\dot{\mathrm{VE}} / \dot{\mathrm{V}} \mathrm{O}_{2}$ at peak exercise was $22.3-41.6$ (median $29 \cdot 8$ ). $\mathrm{VE} / \mathrm{VCO}_{2}$ correlated significantly with $\mathrm{Vo}_{2} \max$ : $R=-0.53, p<0.002$. Figure 1 shows the curvilinear relation; at values of $\mathrm{Vo}_{2}$ max more than $18-20 \mathrm{ml} / \mathrm{kg} / \mathrm{min} \dot{\mathrm{VE}} / \dot{\mathrm{VCO}}_{2}$ was within the normal range, but at values less than this $\dot{V E}_{E}$ $\mathrm{VCO}_{2}$ rose steeply as $\dot{\mathrm{V}} \mathrm{O}_{2} \max$ fell. When $\mathrm{Vo}_{2} \max$ was less than $20 \mathrm{ml} / \mathrm{kg} / \mathrm{min}$ the correlation between $\dot{\mathrm{VE}} / \dot{\mathrm{VCO}}_{2}$ and $\dot{\mathrm{VO}}_{2} \max$ is even stronger: $R=-0.62, p<0.001$ (linear regression equation:

$$
\left.\dot{\mathrm{VE}} / \dot{\mathrm{VCO}}_{2}=40.7-0.7\left(\dot{\mathrm{Vo}}_{2} \max \right)\right) \text {. }
$$

The ratio $\dot{V} / \dot{V}_{E}$ at peak exertion also correlated with $\mathrm{Vo}_{2} \max : \mathrm{R}=-0.58, \mathrm{p}<$ 
Table 3 Results (range (median)) of cardiopulmonary exercise testing in patients and healthy controls

\begin{tabular}{|c|c|c|}
\hline Variable & $\begin{array}{l}\text { Patients } \\
(n=47)\end{array}$ & $\begin{array}{l}\text { Healthy controls } \\
(n=1009)\end{array}$ \\
\hline $\begin{array}{l}\text { Exercise duration }(\mathrm{min}) \\
\dot{\mathrm{V}} \mathrm{O}_{2} \mathrm{max}(\mathrm{ml} / \mathrm{kg} / \mathrm{min}) \\
\text { Peak ventilation }(\mathrm{l} / \mathrm{min}) \\
\text { Peak respiratory rate }(\text { per min }) \\
\text { End tidal } \mathrm{CO}_{2} \text { at peak exertion }(\%) \\
\dot{\mathrm{V} E} / \dot{\mathrm{V}} \mathrm{CO}_{2} \\
\dot{\mathrm{V} D} / \mathrm{VE} \\
\mathrm{VD} / \text { breath }(\mathrm{ml})\end{array}$ & $\begin{array}{c}3-15(7) \\
9-29(14) \\
18-73(33) \\
21-36(28) \\
4 \cdot 5-5 \cdot 6(5 \cdot 0) \\
22 \cdot 3-41 \cdot 6(29 \cdot 8) \\
0 \cdot 14-0 \cdot 55(0 \cdot 35) \\
149-843(393)\end{array}$ & $\begin{array}{c}8-22(15) \\
25-93(42) \\
35-137(79) \\
24-38(30) \\
3 \cdot 7-6 \cdot 1(5 \cdot 1) \\
16 \cdot 9-35 \cdot 8(25 \cdot 0) \\
0 \cdot 02-0 \cdot 65(0 \cdot 26) \\
490-1740(660)\end{array}$ \\
\hline
\end{tabular}

$\mathrm{V}_{2}$ max, peak oxygen consumption averaged over the final minute of a maximal exercise test $\dot{\mathrm{V}} \mathrm{E} / \mathrm{VCO}_{2}$, ratio of minute ventilation to minute production of carbon dioxide; $\dot{\mathrm{V}} \mathrm{D} / \dot{\mathrm{V}} \mathrm{E}$, ratio of dead space ventilation to total ventilation; $\mathrm{VD} / \mathrm{breath}$, dead space ventilated per breath.

0.001 . Dead space per breath $(\mathrm{VD} /$ breath) at peak exertion correlated weakly with $\mathrm{V}_{2} \max$ : $\mathrm{R}=+0.34, \mathrm{p}<0.05$.

Blood oxygen saturation was normal in all patients at rest $(91 \%-97 \%)$. In 23 of the 47 patients, ear lobe oxygen saturation fell by $1 \%-6 \%$ from resting state to peak exertion, with rapid recovery to the resting value within two minutes of the end of exercise. In the remaining 24 patients, oxygen saturation did not change significantly. There was no correlation between $\dot{\mathrm{V}} / \dot{\mathrm{V}} \mathrm{CO}_{2}$ and change in oxygen saturation.

\section{CONTROLS}

Peak oxygen consumption $\left(\dot{\mathrm{V}}_{2} \mathrm{max}\right)$ ranged from 25 to 93 (median 42) $\mathrm{ml} / \mathrm{kg} / \mathrm{min}$. Table 3 gives the results of exercise testing and the respiratory variables calculated from the exercise data. $\dot{\mathrm{VE}} / \dot{\mathrm{V}} \mathrm{CO}_{2}$ at peak exercise ranged from 16.9 to $35 \cdot 8$ (median $25 \cdot 0$ ). $\dot{\mathrm{VE}} / \dot{\mathrm{V}} \mathrm{CO}_{2}$ was weakly related to exercise capacity $\mathrm{Vo}_{2} \max (\mathrm{r}$ $=-0.11, \mathrm{p}<0.0003)$. Age and body weight (body mass index) were related to $\mathrm{Vo}_{2}$ max; after adjustment for age and weight by multiple linear regression analysis, the association was only marginally significant $(p=0.05)$.

The ratio $\dot{V}_{D} / \dot{V}_{E}$ at peak exertion was 0.02 $0 \cdot 65$, median $0 \cdot 26$. VD/VE was weakly related to $\dot{\mathrm{V}} \mathrm{o}_{2} \max (\mathrm{r}=+0.1, \mathrm{p}<0.001)$. Dead space per breath $(\mathrm{VD} /$ breath) at peak exertion was 49 $1740 \mathrm{ml}$ (median $660 \mathrm{ml}$ ). VD/breath was also weakly correlated with $\dot{\mathrm{Vo}}_{2} \max (\mathrm{r}=+0.08, \mathrm{p}$ $<0.0001)$. These relations remained significant after adjustment for age and body weight.

The correlation coefficients between $\mathrm{Vo}_{2}$ max and $\dot{V} E / \dot{V} O_{2}, \dot{V} D / \dot{V} E$, and $V D /$ breath though statistically significant were only small. In a large scale study it is the magnitude of the association, not the significance, that is clinically relevant. Division of the 1009 controls into deciles of $\mathrm{VO}_{2}$ max showed that the mean

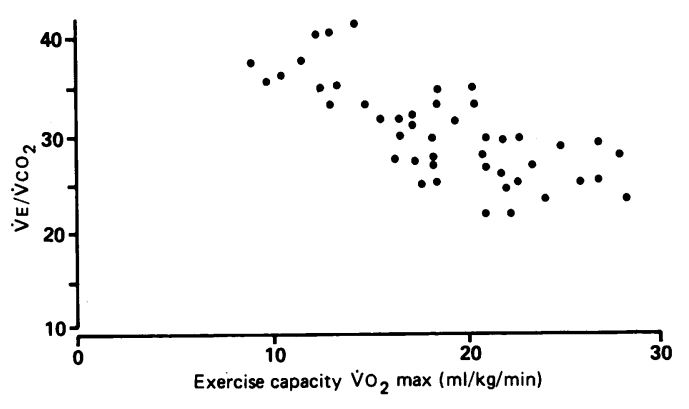

value of $\dot{\mathrm{V}} / \dot{\mathrm{VCO}}_{2}$ was $26 \cdot 1$ in the lowest decile and 24.6 in the highest decile. Similarly, the mean value of $\dot{V}_{D} / \dot{V}_{E}$ was 0.29 in the lowest decile and 0.24 in the highest decile, and $\mathrm{VD} /$ breath was $590 \mathrm{ml}$ in the lowest and $680 \mathrm{ml}$ in the highest decile.

\section{OVERALL RELATION BETWEEN $\dot{\mathrm{V}} \mathrm{E} / \dot{\mathrm{V}} \mathrm{CO}_{2}$ AND $\dot{\mathrm{V}} \mathrm{O}_{2} \mathrm{MAX}$}

Figure 2 shows data on the $\dot{V} E / \mathrm{V} \mathrm{CO}_{2}$ from the controls and from patients with chronic left heart failure. The mean ages of the two groups differ and in the large group of controls the relation of $\dot{\mathrm{VE}} / \dot{\mathrm{V}} \mathrm{O}_{2}$ to $\dot{\mathrm{V}}_{2} \mathrm{max}$ was adjusted for the effects of age by multiple linear regression analysis. Figure 3 shows the ratio of pulmonary dead space ventilation to total ventilation $(\dot{V} D /$ $\dot{V} E)$ and figure 4 shows the total dead space per breath (VD/breath).

\section{Discussion}

The mechanisms of dyspnoea and of hyperpnoea in chronic left heart failure are poorly understood. Pulmonary venous hypertension may be the major mechanism causing breathlessness in acute left heart failure, but this does not seem to be the case in chronic heart failure. There is little correlation between pulmonary wedge pressure at rest or during exercise and exercise capacity. ${ }^{5}$ Whether exercise is limited by dyspnoea or by fatigue depends upon the type of exercise rather than the peak level of pulmonary wedge pressure attained. ${ }^{5}$ When submaximal and maximal exercise tests are performed, both forms of exercise are terminated at similar levels of ventilation, ${ }^{11}$ yet if the primary stimulus to excessive ventilation during exercise was an acute increase in pulmonary venous pressure, then the increase in ventilation would be expected to have been greater during the prolonged submaximal test. In both long term and short term drug studies there is often a dissociation between the haemodynamic effects (including changes in pulmonary wedge pressure) and changes in exercise capacity and in dyspnoea. ${ }^{16-18}$

The abnormally increased ventilatory response to exercise in chronic heart failure is well documented; patients with chronic heart failure ventilate more than healthy individuals at the same external work load. ${ }^{6-8}$ Exercise hyperpnoea has also been described in patients with severe longstanding mitral stenosis. ${ }^{19} \mathrm{It}$ has been suggested that the dyspnoea of such patients during exercise might be causally related to this increased ventilation. ${ }^{11}$ Several underlying mechanisms have been proposed including the stimulation of chemoreceptors by systemic lactic acidosis, ${ }^{610}$ the stimulation of muscle metabolic receptors by local skeletal muscle acidosis, the release of carbon dioxide by buffers, altered arterial $\mathrm{PCO}_{2}$ control, and changes in lung compliance due to congestion and/or chronic fibrosis. ${ }^{20-22}$

Analysis of respiratory gas exchange during exercise has proved useful to examine these hypotheses. ${ }^{23-26}$ In healthy individuals during exercise, ventilation is linearly related to the minute production of carbon dioxide. ${ }^{11}$ In 


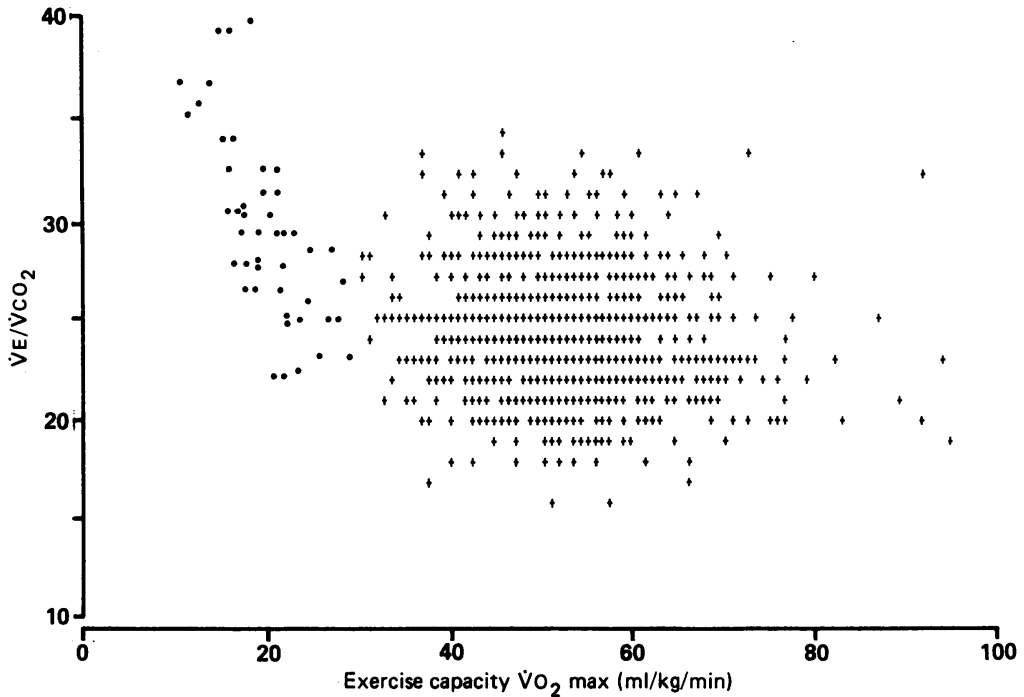

Figure 2 Relation between $\dot{V} E / \dot{V}_{C_{2}}$ and $\dot{V}_{2}$ max in patients and healthy controls.

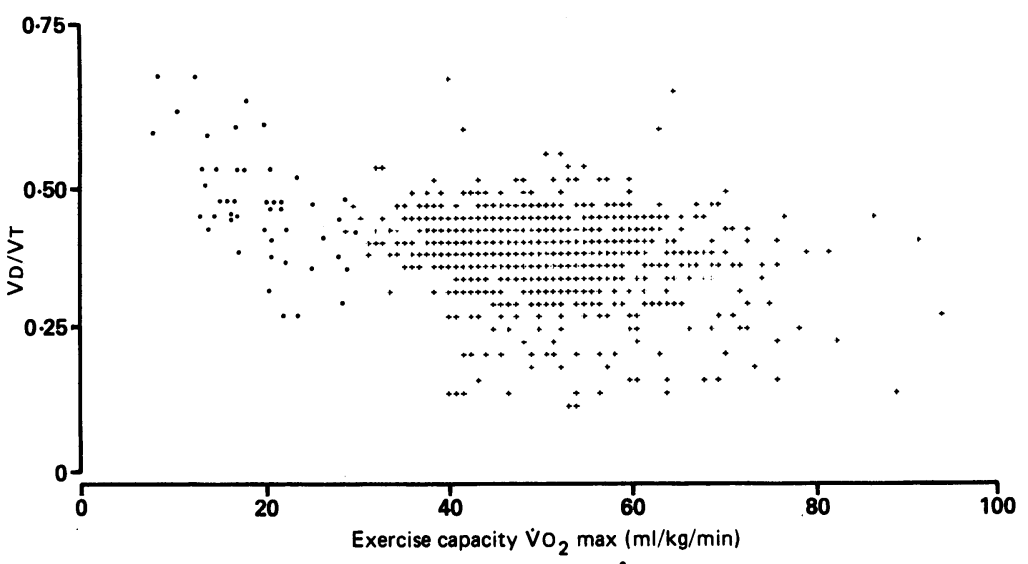

Figure 3 Relation between $\dot{V} D / \dot{V} E$ and $\dot{V} O_{2}$ max in patients and healthy controls.

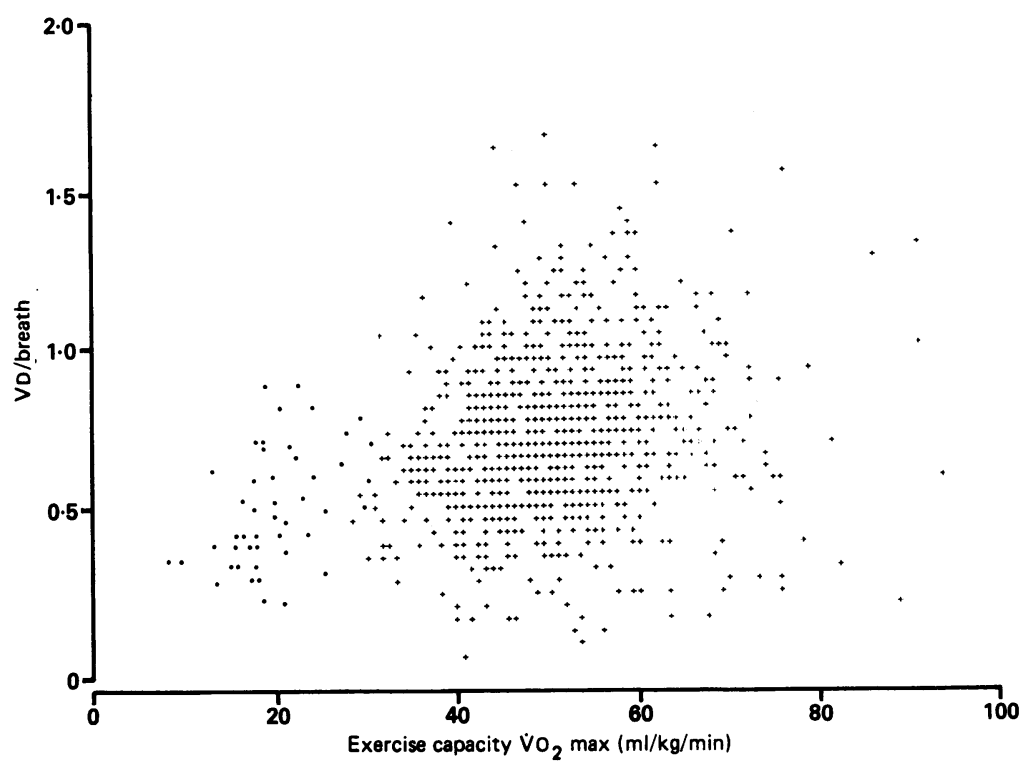

Figure 4 Relation between $V D / b r e a t h$ and $\dot{V}_{2}$ max in patients and healthy controls.

chronic left heart failure the slope of this relation is greatly increased. ${ }^{20}$ This suggests that hyperpnoea cannot be solely the result of higher carbon dioxide production, but must involve one of three possibilities. First, excessive ventilation so as to lower mean arterial $\mathrm{PCO}_{2}$, perhaps in response to lactic acidosis; second, increased ventilation of the anatomical dead space by a rapid shallow pattern of breathing; third, increased ventilation of physiological dead space. Analysis of respiratory gas exchange and in particular of $\dot{V} E /$ $\mathrm{VCO}_{2}$ and $\dot{V} \mathrm{D} / \dot{\mathrm{V}} \mathrm{E}$ allows inferences to be made about gas exchange, dead space, and the matching of ventilation to perfusion.

In the present study we have confirmed previous reports of increased $\dot{\mathrm{VE}} / \mathrm{V} \mathrm{CO}_{2}$ during exercise. ${ }^{9}{ }^{10}$ End tidal carbon dioxide, corrected by the Jones formula to give an estimate of mean arterial $\mathrm{PCO}_{2}$, is the same in patients with chronic left heart failure and healthy controls, implying normal control of arterial $\mathrm{PCO}_{2}$ in severe heart failure despite abnormal ventilation. Applying the Bohr equation to the data shows that the increase in $\mathrm{VE} / \dot{\mathrm{V}} \mathrm{CO}_{2}$ represents an increase in the ratio of dead space ventilation to total ventilation $\left(\dot{V}_{D} / \dot{V} E\right)$.

$\dot{V}_{D} / \dot{V}_{E}$ is higher in the patients with heart failure than in the healthy individuals (table 3 ). Theoretically this might be because a rapid shallow pattern of breathing increases the proportion of dead space ventilation, but this is not the case because respiratory rate at peak exertion was similar in patients with chronic left heart failure and in healthy individuals. Anatomical dead space is not different in chronic heart failure from normal subjects, and therefore physiological dead space must be increased.

Calculated dead space per breath (VD/ breath) varies widely between individuals within both the control group and in patients with chronic heart failure, and there is no significant difference between the groups. This may be because increased $\dot{V} D / \dot{V} E$ in chronic heart failure is offset by the lower tidal volume at peak exertion (itself the product of a lower peak minute ventilation and normal or slightly raised respiratory rate at peak exertion).

The mechanisms of increased $\dot{V} E / \dot{V} O_{2}$ and $\dot{V}_{D} / \dot{V}_{E}$ in severe chronic left heart failure have not been elucidated. It has been suggested that chronic pulmonary congestion, damage, and perhaps chronic diffuse fibrosis contribute. ${ }^{27}$ Significant correlations between $\dot{\mathrm{V}} \mathrm{E} / \dot{\mathrm{V}} \mathrm{CO}_{2}$, mean pulmonary artery pressure, and pulmonary vascular resistance were found in one study $^{28}$ but not in another study. ${ }^{29}$ An alternative explanation is that patients with chronic left heart failure and increased $\dot{\mathrm{V}} / \dot{\mathrm{V}}_{\mathrm{CO}}$ develop subclinical or even overt pulmonary oedema during exertion. Because oxygen is approximately 20 times less diffusable than is carbon dioxide in a fluid film, ${ }^{30}$ a degree of pulmonary oedema sufficient to cause abnormalities in $\dot{\mathrm{VE}} / \dot{\mathrm{V}} \mathrm{CO}_{2}$ would be expected to cause proportionately greater abnormalities in oxygen uptake. Important arterial hypoxaemia, however, was not a finding of the present study; furthermore, there was no correlation between the ratio $\dot{\mathrm{VE}} / \mathrm{VCO}_{2}$ and the change in oxygen saturation with exercise in individual patients.

The correlation between $\dot{\mathrm{V}} / \mathrm{V}_{\mathrm{CO}}$ and $\mathrm{Vo}_{2} \max$ in patients with heart failure confirms the reports of Fink et $a^{29}$ and of Buller and Poole-Wilson. ${ }^{31}$ In these studies, however, few patients had a $\mathrm{VO}_{2}$ max of greater than $20 \mathrm{ml} / \mathrm{kg}$ / min and so the relation between $\dot{\mathrm{VE}} / \mathrm{VCO}_{2}$ and 
$\dot{\mathrm{V}} \mathrm{O}_{2} \mathrm{max}$ was not studied over a wide range of $\dot{\mathrm{V}} \mathrm{O}_{2} \max$. Because end tidal carbon dioxide and arterial $\mathrm{PCO}_{2}$ were not measured, the ratio $\mathrm{VD} /$ $\dot{V} E$ could not be calculated in these studies though it was suggested that physiological dead space was increased. ${ }^{31}$

Regression analysis showed that in patients with chronic heart failure $\dot{\mathrm{V}} / \dot{\mathrm{V}}_{\mathrm{CO}_{2}}$ and $\dot{\mathrm{V}} \mathrm{D} / \dot{\mathrm{V}}_{\mathrm{E}}$ depended strongly on exercise capacity as assessed by $\mathrm{VO}_{2} \max$. In the controls, however, the relation between $\dot{V} E / \dot{V} O_{2}, \dot{V} D / \dot{V} E$, and $\dot{\mathrm{V}} \mathrm{O}_{2} \mathrm{max}$ over a wide range of values of $\dot{\mathrm{Vo}}_{2} \max$ was very weak. The difference might simply reflect the difference between health and a disease state. The values of $\dot{\mathrm{VE}} / \mathrm{VCO}_{2}$ in patients with mild symptoms of heart failure and reasonable exercise capacity $\left(\dot{\mathrm{V}}_{2} \mathrm{max}>20 \mathrm{ml} /\right.$ $\mathrm{kg} / \mathrm{min}$ ) resembled those seen in the controls. There was a point of inflection corresponding to a $\dot{\mathrm{Vo}}_{2} \mathrm{max}$ of approximately $20 \mathrm{ml} / \mathrm{kg} / \mathrm{min}$, below which $\dot{V} / \dot{V} \mathrm{CO}_{2}$ rises abnormally and the calculated dead space ratio $\dot{V} \mathbf{D} / \dot{V}_{E}$ increases (figs 2 and 3 ). This suggests that ventilatory abnormalities develop only when chronic left heart failure exceeds a critical level of severity and exercise capacity falls below $\mathrm{Vo}_{2} \max$ of 20 $\mathrm{ml} / \mathrm{kg} / \mathrm{min}$.

In conclusion, it seems that the increase in $\dot{\mathrm{V}} \mathrm{E} / \dot{\mathrm{V}} \mathrm{CO}_{2}$ and $\dot{\mathrm{V}} / \dot{\mathrm{V}} \mathrm{E}$ in patients with chronic left heart failure is caused by pulmonary ventilation-perfusion mismatching: there are zones which are adequately ventilated or even hyperventilated, yet receive little pulmonary blood flow. At present there is no evidence to indicate whether this occurs on a regional or zonal basis or is distributed at alveolar level throughout the lungs. The threshold of exercise capacity and of severity of heart failure for abnormal increases in $\dot{V} E / \dot{V}_{C O_{2}}$ and $\dot{V} D / \dot{V E}$ could be explained by the existence of a critical level of cardiac output response to exercise, necessary to perfuse adequately all ventilated lung zones.

1 Poole-Wilson PA. The origin of symptoms in patients with chronic heart failure. Eur Heart $J 1988 ; 9$ (suppl H):49-53.

2 Hogg JC, Agarwal JB, Gardiner AJ, Palmer WH, Macklem PT. Distribution of airways resistance with developing pulmonary edema in dogs. $J$ Appl Physiol 1972;32:20-4.

3 Depeursinge FB, Depeursinge CD, Boutaleb AK, Feihl F, Perret CH. Respiratory system impedence in patients with acute left ventricular failure: pathophysiology and clinical interest. Circulation 1986;73:386-95.

4 Fransiosa JA, Ziesch S, Willen M. Functional capacity in patients with chronic left ventricular failure: relationship of bicycle exercise performance to clinical haemodynamic characterisation. Am J Cardiol 1979;67:460-6.

5 Lipkin DP, Canepa-Anson R, Stephens MR, Poole-Wilson PA. Factors determining symptoms in heart failure: comparison of fast
6 Weber KT, Kinasewitz GT, Janicki JS, Fishman AP. Oxygen utilization and ventilation during exercise in patients with chronic cardiac failure. Circulation 1982;65:1213-23.

7 Higginbotham MB, Morris KG, Conn EH, Coleman RE, Cobb FR. Determinants of variable exercise performance among patients with severe left ventricular dysfunction. among patients with severe 1 Cardiol 1983;51:52-60.

8 Wilson JR, Ferraro N. Exercise intolerance in patients with chronic left heart failure: relation to oxygen transport and chronic left heart failure: relation to oxygen transport and

9 ventilatory abnormalities. Am J Cardiol 1983;51:1358-63 analysis of carbon dioxide transport during exercise. Clin analysis of carbon diox
Sci 1967;32:289-98.

10 Whipp BJ. Ventilatory control during exercise in humans. Annu Rev Physiol 1983;45:393-413.

11 Sullivan MJ, Higginbotham MB, Cobb FR. Increased exercise ventilation in patients with chronic heart failure: intact ventilatory control despite haemodynamic and pulmonary abnormalities. Circulation 1988;77:552-9.

12 Davies N, Denison DM. Measurement of metabolic gas exchange and minute ventilation by mass spectrometry alone. Respir Physiol 1979;36:261-7.

13 Jones NL, Robertson DJ, Kane JW. Difference between endtidal and arterial PCO2 in exercise. J Appl Physio 1979;47:954-60.

14 Bohr C. Pulmonary ventilation. Scand Arch Physiol 1891; 2:236.

15 Jones NL. Clinical exercise testing. 3rd ed. Philadelphia: WB Saunders, 1988:34-9.

16 Franciosa JA, Goldsmith SR, Cohn JN. Contrasting immediate and long term effects of Isosorbide Dinitrate on exercise capacity in congestive heart failure. $\mathrm{Am} \mathrm{J} \mathrm{Cardio}$ 1980;69:559-66.

17 Franciosa JA,Dunkman B, Leddy CL. Haemodynamic effec of vasodilators and long term response in heart failure. $J$ Am Coll Cardiol 1984;3:1521-30.

18 Saskind SI, Sonnenblick EH, Forman R, Schever J, Le Jemtel TH. Acute substantial benefit of inotropic therapy with amrinone on exercise haemodynamics and metabolism in severe congestive heart failure. Circulation $1981 ; 64: 966-73$.

19 Frank RN, Chugell DW, Gaensler EA, Ellis LB. Ventilatory studies in severe mitral stenosis. Am JMed 1953;15:60-75.

20 Reuben SA, Brown HV. Ventilation and the gas exchange during exercise in severe chronic heart failure $A m$ Rev during exercise in severe chronic
Respir Dis 1984;129(suppl):S63-4.

21 Nery LE, Wasserman K, French W, Oren A, Davis JA Contrasting cardiovascular and respiratory responses to exercise in mitral valve and chronic obstructive pulmonexercise in mitral valve and chron

22 Hayward GW, Knott JMS. The effect of exercise on lung distensibility and respiratory work in mitral stenosis. $B r$ distensibility and respira

23 Cohn J. Quantitative testing for the cardiac patient: the value of monitoring gas exchange. Circulation 1987;76(supp VI): VI.1-2.

24 Lipkin DP. The role of exercise testing in chronic hear failure. Br Heart J 1987;58:559-66.

25 Lipkin DP, Perrins J, Poole-Wilson PA. Respiratory gas exchange in the assessment of patients with impaired ventricular function. Br Heart $J$ 1985;54:321-8.

26 Wilson JR, Fink LI, Ferraro N, Dunkman WB, Jones RA Use of maximal bicycle exercise testing with respiratory gas analysis to assess exercise performance in patients with gas analysis to assessiure secondary to coronary artery disease or to idiopathic dilated cardiomyopathy. $\mathrm{Am}$ Cardiol 1986;58:601-6.

27 Gazetopoulos N, Davies H, Oliver C, Deuchar D. Ventilation and haemodynamics in heart disease. Br Heart tion and haem

28 Takanawa Y, Orimoto T. Pulmonary vascular changes and ventilation in chronic heart failure [Abstract]. J Am Coll ventilation in chronic heart

29 Fink LI, Wilson JR, Ferraro N. Exercise ventilation and pulmonary artery wedge pressure in chronic stable congestive heart failure. Am J Cardiol 1986;57:249-53.

30 Lambertsen CJ. The atmosphere and gas exchanges with the lungs and blood. In: Mountcastle VB, ed. Medical physiology 13th ed. Saint Louis: CV Mosby, 1974:1390.

31 Buller NP, Poole-Wilson PA. Mechanism of the increased ventilatory response to exercise in patient 